Süleyman Demirel Üniversitesi Fen Edebiyat Fakültesi Fen Dergisi

Atıf için / For Citation: G. Sevim, Y. A. Üncü, M. Canpolat, "Difüz optik tomografi sistemlerinde kullanılan geri çatım algoritmaları için iterasyon sayısını belirmede alternatif bir yöntem", Süleyman Demirel Üniversitesi Fen Edebiyat Fakültesi Fen Dergisi, 16(1), 246-258, 2021.

\title{
Difüz Optik Tomografi Sistemlerinde Kullanılan Geri Çatım Algoritmaları için İterasyon Sayısını Belirmede Alternatif Bir Yöntem
}

\author{
Gençay Sevim ${ }^{* 1,2}$, Yiğit Ali Üncü ${ }^{3}$, Murat Canpolat ${ }^{3}$ \\ ${ }^{1}$ Ufuk Üniversitesi, Sağllk Hizmetleri Meslek Yüksekokulu, 06520, Ankara, Türkiye \\ ${ }^{2}$ Eskişehir Teknik Üniversitesi, Ileri Teknolojiler AD., 26555, Eskişehir, Türkiye \\ ${ }^{3}$ Akdeniz Üniversitesi, Tıp Fakültesi, Biyofizik AD., 07058, Antalya, Türkiye \\ *yazışlan yazar e-posta: gencay.sevim@ufuk.edu.tr
}

(Alinı̧ / Received: 21.04.2021, Kabul / Accepted: 07.05.2021, Yayımlanma / Published: 27.05.2021)

Özet: Difüz Optik Tomografi (DOT) sistemleri optik medikal görüntüleme yöntemlerindendir. DOT sistemlerinin görüntü oluşturma aşaması oldukça önemlidir. Bu çalışma da DOT sisteminde kullanılan iteratif geri çatım algoritmaları için ideal iterasyon sayının literatürdeki metotlara alternatif bir metot ile belirlenebilmesi amaçlanmaktadır. Bu metodun, kontrastgürültü oranı (Contrast to Noise Ratio, CNR) metoduna benzer bir çalışma prensibi vardır. $\mathrm{Bu}$ metodu test edebilmek için MATLAB programı ile simülasyon deneyleri yapılmıştır. Simülasyon verisi oluşturulduktan sonra CNR benzeri iterasyon belirleme algoritması kullanılarak belirlenen iterasyon sayısı ile geri çatım algoritmaları modellenen verinin görüntülerini oluşturmuştur. Bu çalışmada geliştirilen iterasyon belirleme algoritması Kesikli Eşlenik Gradyent (Truncated Conjugate Gradient, TCG), Çift Eşlenik Gradyent (Bi-Conjugate Gradient) ve Transpozu Olmadan Kısmen Minimum Rezidüel (Transpose Free Quasi Minimal Residual, TFQMR) algoritmalarına entegre edilmiştir.

Anahtar kelimeler: Difüz optik tomografi, İterasyon sayısı, Geri çatım algoritmaları, Kontrast gürültü oran1

\section{An Alternative Method for Determining the Iteration Number for Reconstruction Algorithms Used in Diffuse Optical Tomography Systems}

\begin{abstract}
Diffuse Optical Tomography (DOT) systems are optical medical imaging methods. The image reconstruction stage of DOT systems is very important. This study is aimed to determine the ideal number of iterations for the iterative reconstruction algorithms used in the DOT system with an alternative to the methods in the literature. This method has a similar working principle to the Contrast to Noise Ratio (CNR) method. In order to test this method, simulation experiments have been carried out with MATLAB. After the simulation data was created, the reconstruction algorithms created the images of the simulated data with the number of iterations determined using the CNR-like iteration determination algorithm. The iteration determination algorithm developed in this study has been integrated into Truncated Conjugate Gradient (TCG), Bi-Conjugate Gradient, and Transpose Free Quasi Minimal Residual (TFQMR) algorithms.
\end{abstract}

Key words: Diffuse optical tomography, Iteration number, Reconstruction algorithms, Contrastto-Noise ratio 


\section{Giriș}

Difüz optik tomografi (DOT), medikal görüntüleme alanında diğer görüntüleme yöntemlerine alternatif olarak ortaya atılmıştır. Günümüzde de birçok alanda DOT ile ilgili çalışmalar devam etmektedir[1-3]. DOT sistemleri, 3 temel uzayda çalışır. Bunlar zaman uzayı, frekans uzayı ve sürekli dalgadır[4]. Zaman uzayında çalışan sistemlerde 1şık kaynağı olarak atımlı lazerler kullanılır. Zamansal nokta dağılım fonksiyonları ölçülür ve bunlar kullanılarak dokuların uzamsal olarak dağılmış absorpsiyon ve saçılma katsayıları belirlenir [5]. Frekans uzayında çalışan sistemlerde ise genlik modülasyonlu sürekli bir 1şık kaynağı, belirli bir frekans aralığında kullanılır. Işık yoğunluğu ve frekanstaki faz kayması dokunun optik özelliklerinin belirlenmesini sağlar[6]. Son olarak sürekli dalga DOT sistemlerinde, sabit genlikli bir 1şık kaynağ kullanılır. Dağınık olarak geri yansıyan veya iletilen 1şık yoğunluğu ölçülür. Ölçüm sonuçları dokunun optik özelliklerini belirlenmesini sağlar[7].

Biyolojik dokuların optik özellikleri; absorpsiyon $\left(\mu_{a}\right)$ katsayısı, saçılma $\left(\mu_{s}\right)$ katsayısı, anizotropi ve dokuların kırılma indeksleri ile karakterize edilir[8, 9]. DOT sistemleri, bir biyolojik dokunun görüntüsünü oluşturmak için dokunun optik özelliklerinden faydalanır. Örneğin; sürekli dalga DOT sistemleri, dokudaki kanlanmanın meydana getirdiği absorpsiyon değişimininden yararlanır.

Bir doku içinde 1şığın dağılımı, dokunun optik özelliklerine bağlıdır ve matematiksel olarak Radiyatif Transfer Denklemi (RTD) ile ifade edilir[8, 9]. Fakat bu denklemin analitik olarak çözümü zor olduğu için belli yaklaşımlar yapılarak denklem 1'deki gibi lineer hale getirilir [9-11].

$$
y=A x
$$

Denklem 1'de $y$, DOT sistemiyle elde edilen ham ölçüm verilerinin matrisini, $A$, Monte Carlo simülasyonlariyla elde edilen katsayılar matrisini ve $x$ ise bilinmeyen matrisini ifade etmektedir. DOT sisteminin matrisleri “Kötü Koşullu (ill-condition)'dur”. Kötü koşullu matris sistemlerinin çözümü oldukça önemlidir. DOT sistemlerinde ham veriler alındıktan sonra lineer kötü koşullu matris denklemini çözerek görüntü elde etme aşamasında birçok geri-çatım algoritması kullanılmaktadır. Bu aşamada Krylov alt uzay geri çatım algoritmaları, büyük ölçekli matris denklem sistemlerine daha iyi bir çözüm sundukları kanıtlanmıştır[12, 13]. Önceki çalışmalarımızda, DOT sistemimize 7 farklı geri çatım algoritması uyarlanıp entegre edilmiştir. Bu algoritmalar; Cebirsel Geri Çatım Tekniği (Algebraic Reconstruction Technique, ART), Eş zamanlı Yinelemeli Geri Çatım Tekniği (Simultaneous Iteration Reconstruction Technique, SIRT), Tekil Değer Ayrışımı (Singular Value Decomposition, SVD), Kesikli Eşlenik Gradyent (Truncated Conjugate Gradient, TCG), Çift Eşlenik Gradyent (Bi-Conjugate Gradient, BiCG), Transpozsuz Kismi Minimum Rezidüel (Transpose-free Quasi Minimal Residual, TFQMR)'dır [13-15]. Bu algoritmalar, iteratif teknikler olduğu için çözüme düzgün bir şekilde yaklaşılan iterasyon sayısının doğru bir şekilde belirlenmesi gerekmektedir. Literatürde, en sık kullanılan yöntem L-eğrisi (L-Curve) yöntemidir. Leğrisi yönteminde eğrideki iterasyon sayısını doğru bir şekilde tespit edebilmek gerekmektedir[16]. Fakat bunun tespiti çoğu zaman zor olmaktadır [17].

$\mathrm{Bu}$ çalışmada, L-eğrisi yöntemine alternatif olarak geliştirdiğimiz bir iterasyon sayısı belirleme yöntemi ele alınmıştır. Çalışma prensibi olarak L-eğrisi yönteminden tamamen farklıdır. Kontrast-gürültü oranı çalışma mantığını temel almıştır[15]. 
Tasarlanan iterasyon sayısı belirleme algoritması en çok kullandığımız TCG, Bi-CG ve TFQMR algoritmalarına uyarlanıp entegre edilmiştir.

\section{Materyal ve Metot}

\subsection{Itterasyon Sayısı Belirleme (ISB) Algoritması}

Literatürde, İSB için kullanılan algoritmalarda genellikle belli düzenleme parametreleri kullanılır. $\mathrm{Bu}$ algoritmalardan en çok kullanılan L-eğrisi yöntemidir. L-eğrisi yönteminde her bir iterasyonda elde edilen çözüm kümesinin $(x)$ ve rezidülerin normları alınarak L şeklinde bir grafik elde edilir. Bu grafikte L eğrisinin köşesindeki en uygun nokta seçilir ve bu noktanın, çözüm için ideal iterasyon sayısını verdiği düşünülerek işleme sokulur. Fakat bu noktayı bulmak bazı durumlarda zor olabilmektedir[17]. Bu çalışmada kullanılan metodun çalışma prensibinde, L-eğrisi yönteminin çalışma prensibinden farklı olarak çözüm kümelerinin normu alınmıyor.

Yapılan her bir deneyin çözüm kümeleri detaylı olarak incelendiğinde görüntünün oluştuğu kısımların verilerinin ortam verilerinden çok daha yüksek değerlere sahip olduğu anlaşılmıştır. Buna bağlı olarak önceki çalışmalarımızda yapılan hem simülasyon hem de in-vitro deney verilerinin bunu doğrular nitelikte olduğu görülmüştür. $\mathrm{Bu}$ aşamada DOT sistemiyle elde edilen ham verilerde dokudaki lezyonlardan elde edilen veriler ile ortam verileri arasındaki fark ne kadar büyük olursa o kadar iyi görüntüler elde edildiği fark edilmiştir. Bu sebeple bu ayrımı daha iyi yapabilecek bir kontrast gürültü oranı (Contrast to Noise Ratio, CNR) benzeri bir algoritma tasarland1[15]. $\mathrm{Bu}$ algoritmanın çalışma sisteminde; geri çatım algoritmalarının her bir iterasyonunda elde edilen sonucun kaydedilerek sonrasında hızlı bir tarama yapılarak en yüksek farkı veren iterasyon sayısının görüntü için uygun iterasyon sayısı olduğu tespit edilmektedir. Sonrasında elde edilen iterasyon sayıs1 kullanılarak sistem tarafından otomatik olarak geri çatım algoritmalarında kullanılarak görüntü oluşturulmaktadır.

CNR benzeri İSB algoritmasında "Gaussian filtresi" kullanılmaktadır. Uygulanan filtrenin "sigma" değerleri DOT görüntü verileri incelenerek en uygun şekilde belirlenmiştir. Oluşturulan CNR benzeri İSB algoritması geri çatım algoritmalarına (TCG, BiCG, TFQMR) entegre edilmiştir. Bu aşamada İSB algoritması, geri çatım algoritmalarının ürettiği sonuçları belli bir iterasyon aralığında tarayıp her bir iterasyon verisini (iterasyon sayısını ve değerini) kaydettiği için ve sonrasında da belirlenen iterasyon sayısı ile görüntü verilerini oluşturduğu için sistemin görüntü oluşturma aşamasını kısmen yavaşlatmaktadır. Fakat manuel olarak iterasyon sayısının belirlenmesi aşamasındaki sürenin kısalması ve iterasyon sayılarının diğer İSB algoritmasına nazaran daha net bir şekilde belirlenebilmesi bir avantaj yaratmıştır.

$\mathrm{Bu}$ İSB algoritması belirli iterasyon sayısı aralığını tarayarak en yüksek iterasyon değerine sahip iterasyon sayısını bulur. Her aralık, geri çatım algoritmalarının her birine özgü olarak detaylı analizler sonunda belirlenmiştir. Sonrasında da tespit edilen iterasyon sayısı kullanılarak geri çatım tekniğinin doğru iterasyon noktasındaki çözümü sağlanarak ideal görüntü verileri elde edilir. Algoritma, her iterasyon sayısında üretilen çözüm kümesi için bir iterasyon değeri atar. Bu çözüm kümelerinin kendilerine ait iterasyon değerleri, görüntü verilerine ne kadar yaklaşıldığını belli bir tolerans değerleri ile kontrol edecek şekilde karakterize edilmiştir. Bu tolerans değerlerini sigma parametreleri belirler. 


\subsection{Geri Çatım Algoritmaları}

\subsubsection{Kesikli Eşlenik Gradyent (TCG)}

TCG yöntemi bir alt uzay metodudur. Hermitian bir matris içeren simetrik, pozitif lineer matris sistemlerine çözüm getiren bir yöntemdir[18]. TCG yöntemi büyük sparse matris sistemlerini çözebilmek için iteratif bir yöntem olarak kullanır. TCG metodunun temelinde bir uzaydaki ortagonaliteden yararlanarak uzaydaki bir noktanın yönlerini tespit eden Conjugate Direction metodu vardır. Denklem 2 ve 3'te TCG algoritmasının çalışma prensibi olarak çözüme ulaşması için her bir iterasyonda elde edilen çözüm kümelerinin rezidülerden $(r)$ yararlanarak bulunan arama vektörlerini $(p)$ kullanmaktadır. Arama vektörleri, TCG metudunda sistemin çözümünü bulabilmek için Krylov alt uzayında katsayılar matrisi ve rezidüler kullanılarak elde edilen çözüm parametresidir. Rezidülerin her biri kendisinden önceki tüm arama vektörlerine ve tüm rezidülere ortagonaldir.

$$
\begin{aligned}
V_{i} & =\operatorname{span}\left(p_{0}, A p_{0}, A^{2} p_{0}, \ldots, A^{i-1} p_{0}\right) \\
& =\operatorname{span}\left(r_{0}, A r_{0}, A^{2} r_{0}, \ldots, A^{i-1} r_{0}\right)
\end{aligned}
$$

Denklem 2 ve 3 'te rezidüleri ve arama vektörlerini ifade eden uzaylara Krylov alt uzayları denilir. TCG algoritması çözüme ulaşırken ağırlık matrisinin transpozunun öz vektörünü de kullanmak zorundadır. $\mathrm{Bu}$ yüzden her iterasyonda ağırlık matrisinin transpozu işleme sokulur. TCG algoritması genel olarak aşağıdaki gibi çözüm üretir[18].

$$
\begin{gathered}
p_{0}=r_{0}=b-A x_{0} \\
\alpha_{i}=\frac{r_{i}^{T} r_{i}}{p_{i}^{T} A p_{i}} \\
x_{i+1}=x_{i}+\alpha_{i} p_{i} \\
r_{i+1}=r_{i}-\alpha_{i} A p_{i} \\
\beta_{i+1}=r_{i+1}^{T} r_{i+1} / r_{i}^{T} r_{i} \\
p_{i+1}=r_{i+1}+\beta_{i+1} p_{i}
\end{gathered}
$$

Denklem 5'te $\alpha$, ortogonal ilişkinin bir sabitini ve Denklem 8'de $\beta$, Gram-Schmidt sabitini ifade eden parametrelerdir. Denklem 7 yenilenen rezidüleri ve denklem 9 yenilenen arama vektörlerini hesaplar. Her bir iterasyonda parametreler yenilenerek yeni iterasyon için hazırlanır. Denklem 6'da her iterasyonda elde edilen bilinmeyenler matrisinin eşitliği verilmiştir. İterasyon sayısı belirleme algoritması bu döngüye entegre edilmiştir. Böylece her bir iterasyonun hesapladığı bilinmeyenler matrisi kaydedilerek uygun iterasyon sayıs tayini yapılabilmektedir. 


\subsection{2 Çift Eşlenik Gradyent (BiCG)}

TCG algoritması birçok sistem için çözüm sunabilirken Hermitian olmayan matris sistemleri için iyi bir çözüm sunamamaktadır. Bu sebeple bu tarz sistemlerin çözümü için BiCG algoritması geliştirilmiştir[19-21]. BiCG, bir sisteme çözüm üretebilmek için TCG ile aynı alt uzayları kullanmaktadır. Fakat BiCG algoritması simetrik bir ağırlık matrisine ihtiyaç duymaz. Denklem 10 ve 11 'de gibi BiCG, çözüme ulaşmak için ek iki vektör kullanır.

$$
\begin{aligned}
& r_{i}^{*}=r_{i-1}^{*}-\alpha_{i} A^{T} p_{i}^{*} \\
& p_{i}^{*}=r_{i-1}^{*}-\beta_{i} p_{i-1}^{*}
\end{aligned}
$$

BiCG algoritması Hermitian olmayan matrisleri içeren sistemleri çözebilmek için geliştirmiştir. Fakat Hermitian olmayan sistemleri çözebilmek için geri çatım algoritmalarının karşılaması gereken iki temel özellikten sadece birini karşılar. Bu özelliklerden biri olan her bir iterasyondan gerekli olan düşük ve sabit depolama gereksinimini karşılamaktadır. Buna karşın diğer bir özellik olan Krylov alt uzayı üzerinde bir minimizasyona bağlı olarak çalışması gerektiği özelliğini karşılayamamaktadır. Çünkü BiCG algoritması Galerkin yöntemini temel alarak çalışır. $\mathrm{Bu}$ da bazı durumlarda BiCG algoritmasının sayısal olarak kararsız olmasına ve düzensiz konverjans davranış1 göstermesine sebep olur[15, 22, 23].

\subsubsection{Transpozsuz Kısmi Minimum Rezidüel (TFQMR)}

BiCG algoritmasının bazı durumlarda düzgün çözümler üretememesi üzerine bu eksiliği giderebilmek için TFQMR algoritmasını DOT sistemine uyarladık. TFQMR, çözüme ulaşırken hem ağırlık matrisinin transpozundan yararlanmaz hem de Galerkin yöntemini kullanmaz. Freund ve Nachtigal, BiCG'nin düzensiz konverjans davranışını düzeltebilmek için ilk önce Kısmi Minimum Rezidü (Quasi Minimal Residual) metodunu öne sürmüşlerdir[22]. Fakat bu metot da çözüme ulaşabilmek için ağırlık matrisinin tersine ihtiyaç duymaktadır. Bu yüzden TFQMR algoritması öne sürülerek bu dezavantajın üstesinden gelinmeye çalışılmıştır[23]. TFQMR algoritması Denklem 12 'de gibi bir $S$ matrisi kullanarak Denklem 13 ve 14'teki gibi vektör dizilerini oluşturur.

$$
\begin{gathered}
A^{T} S=S A \\
w_{1}:=S v_{1} /\left\|S v_{1}\right\| \\
w_{n}=\gamma_{n} S v_{n} /\|S v 1\|=S v_{n} /\left\|S v_{n}\right\|
\end{gathered}
$$

“wn" vektör serisi 14. eşitlik kullanılarak elde edildiği için TFQMR ağırlık matrisinin transpozuna ihtiyaç duymaz. TFQMR ideal algoritması aşağıdaki gibidir[15, 23];

$$
x_{m}=\left(1-c^{2}\right) x_{m-1}+c_{m}^{2} \tilde{x}_{m}
$$




$$
\begin{gathered}
v_{m}=\frac{\omega_{m}+1}{\tau_{m}-1} \\
c_{m}=\frac{1}{\sqrt{1+v_{m}^{2}}} \\
\tau_{m}=\tau_{m-1} v_{m} c_{m} \\
d_{m}=\frac{1}{\alpha\lfloor(m-1) / 2\rfloor}\left(\tilde{x}_{m}-x_{m-1}\right) \\
x_{m}=x_{m-1}+\eta_{m} d_{m}, \eta_{m}=c_{m}^{2} \alpha\lfloor(m-1) / 2\rfloor
\end{gathered}
$$

Denklem 16-19'da konverjans için kullanılan parametreler hesaplanır. Denklem 20'de hesaplanan bilinmeyenler matrisi diğer iki algoritmada olduğu gibi her iterasyonda depolanır ve iterasyon sayısı belirleme algoritması ile uygun iterasyon sayısı elde edilir. Sonrasında uygun iterasyon sayısı ile tekrardan geri çatım yapılarak görüntü oluşturulur.

\section{Bulgular}

Bu çalışmada görüntü oluşturma veya kıyaslama yapmanın yanı sıra iterasyon sayısının hem otomatik olarak hem de net bir şekilde belirlenmesi amaçlanmaktadır. İterasyon sayısının belirlenmesi otomatik olarak yapılarak görüntülerden daha hızlı ve hassas bir şekilde uygun iterasyon sayıları belirlenerek görüntüler oluşturulmuştur. 

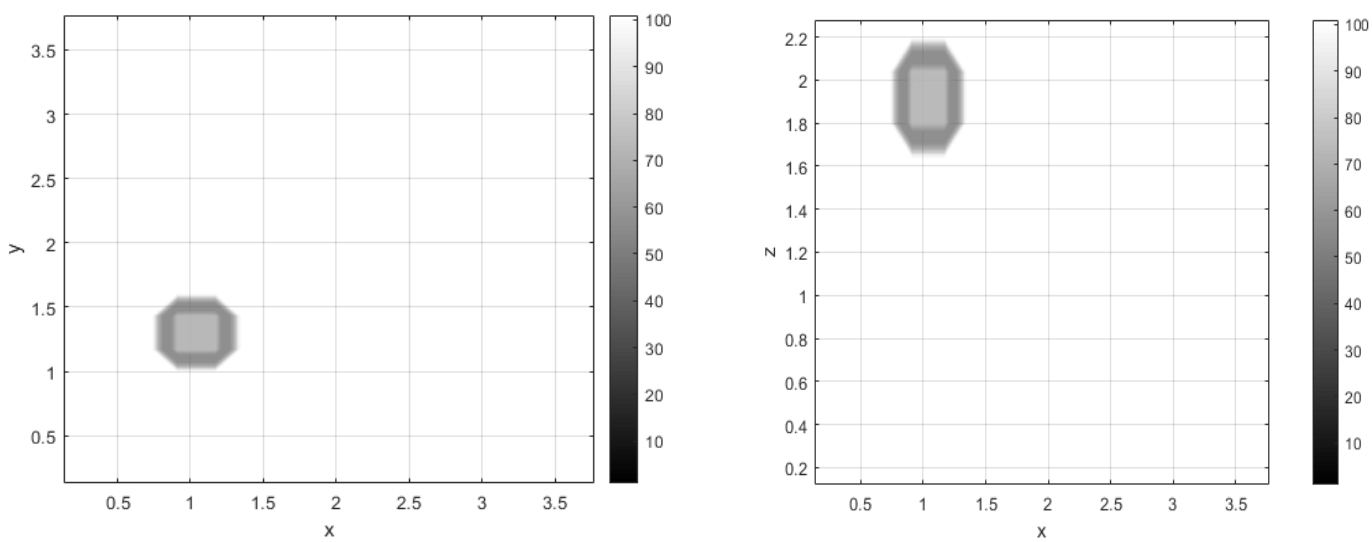

Şekil 1. MATLAB kullanılarak gürültüsüz bir şekilde simüle edilen görüntü (a) XY düzlemindeki, (b) XZ düzlemindeki konumu

Veri matrisi ve simülasyon görüntüsü (Şekil 1), MATLAB 2020a kullanılarak gürültüsüz bir şekilde simüle edilmiş ve sonrasında da geri çatım teknikleriyle görüntüleri oluşturulmuştur (Şekil 2 - 4). Simülasyon verilerinin derinlik bakımından yüzeye yakın ve gürültüsüz oluşturulmasının sebebi bütün geri çatım algoritmalarıyla düzgün görüntüler oluşturulabilmek istendi. Şekil 2'de 3 farklı geri çatım algoritmalarıyla oluşturulan görüntüler verilmiştir. 

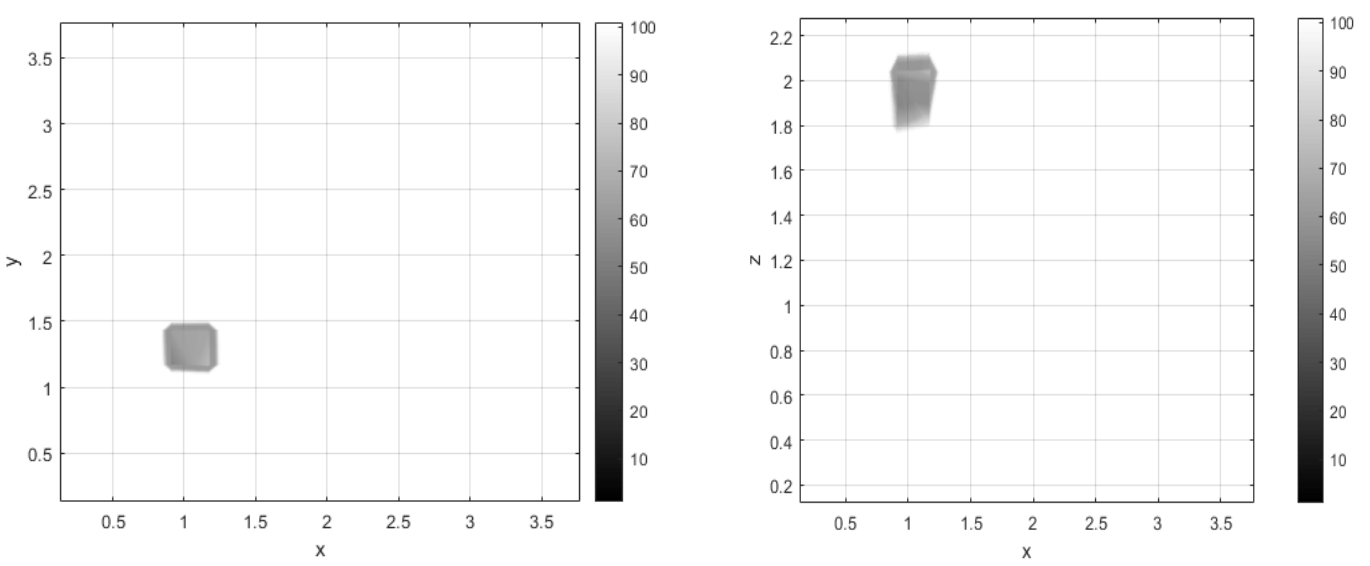

(c)

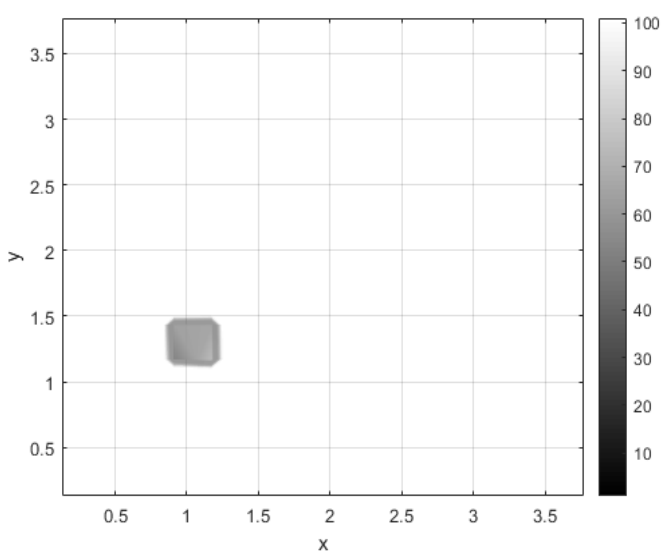

(d)

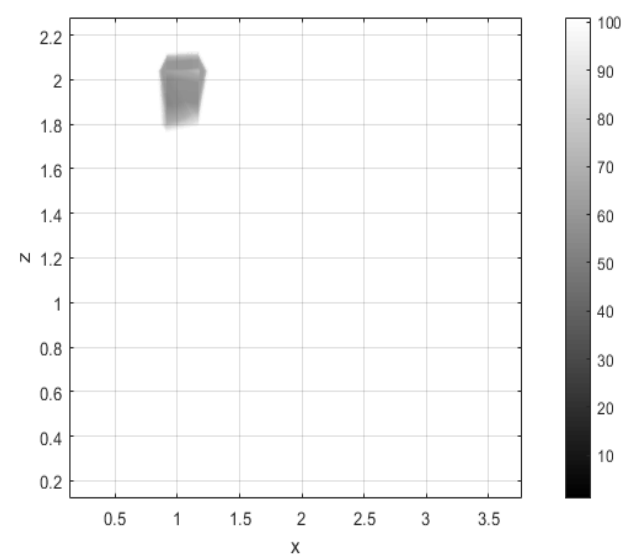

(e) 

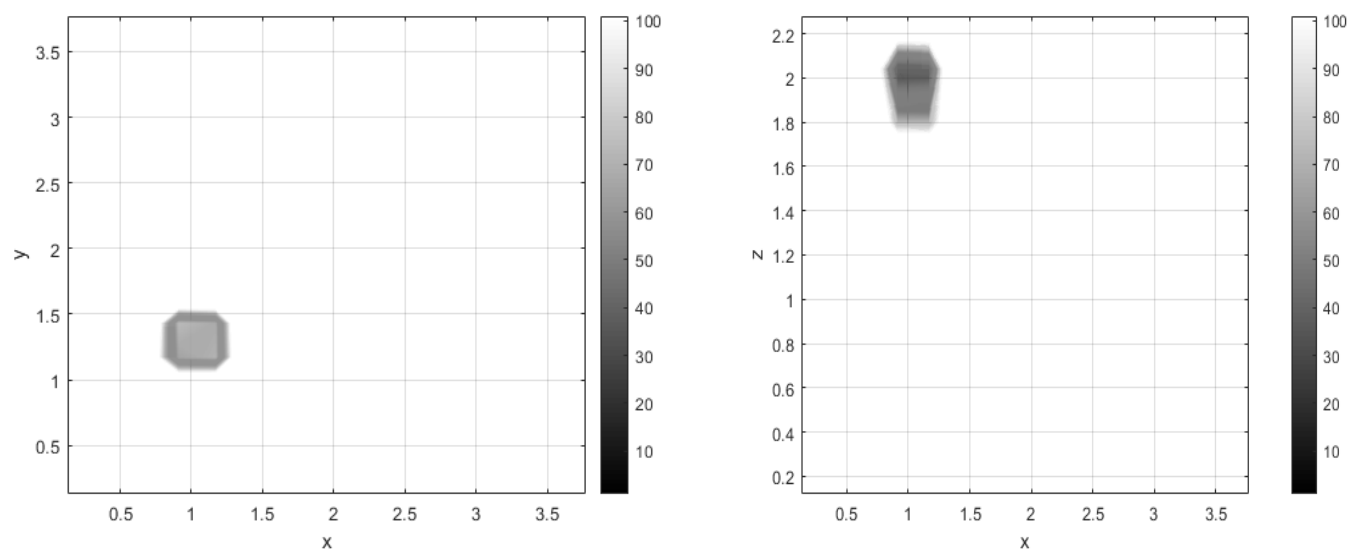

Şekil 2. Simüle edilen parçacığın (a) XY düzlemindeki konumunun, (b) XZ düzlemindeki konumunun TCG ile oluşturulmuş görüntüsü, (c) XY düzlemindeki konumunun (d) XZ düzlemindeki konumunun BiCG ile oluşturulmuş görüntüsü, (e) XY düzlemindeki konumunun (f) XZ düzlemindeki konumunun TFQMR ile oluşturulmuş görüntüsüdür.

Şekil 2 (a) ve (b), Şekil 1'de gösterilen simülasyonun TCG ile 20. iterasyonda oluşturulmuş farklı koordinat düzlemi görüntüleridir. (c) ve (d), simülasyonun BiCG algoritmasıyla 16. iterasyonda oluşturulmuş farklı düzlemlerdeki görüntüleridir. (e) ve (f) ise simülasyonun TFQMR ile 10. iterasyonda oluşturulmuş görüntüleridir. Görüntüler oluşturulurken kullanılan ISB algoritmasının grafikleri Şekil 3-5'te gösterilmiştir. Şekillerdeki iterasyon değerleri, CNR benzeri değerler oldukları için sadece iterasyon sayılarını belirlemek için kullanılırlar.

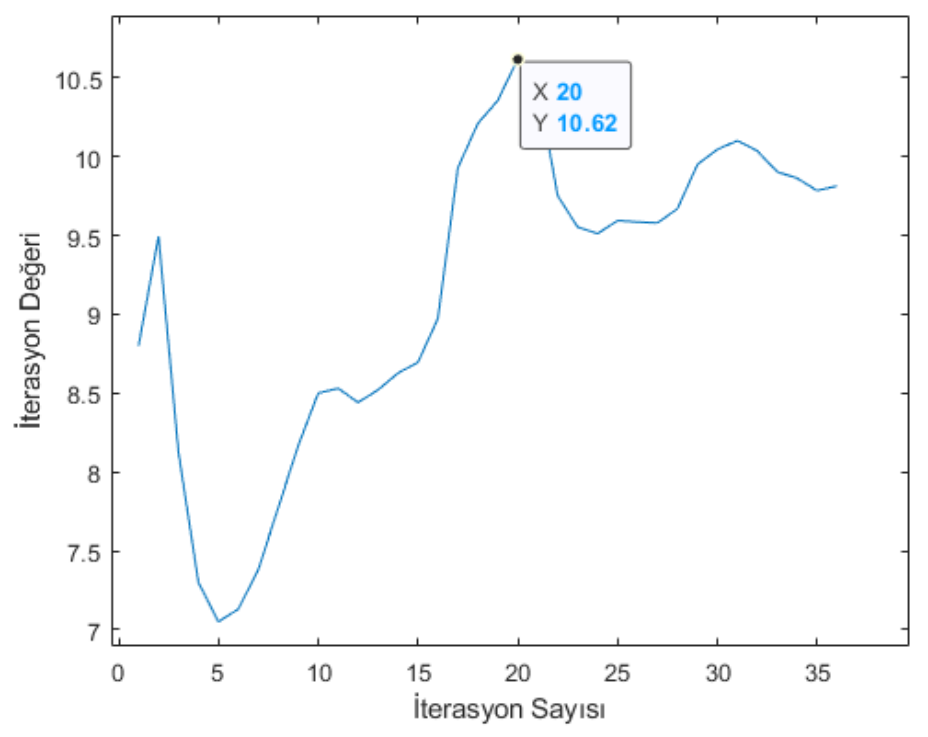

Şekil 3. TCG için kaydedilen iterasyon sayısı belirleme algoritması grafiğgi

Şekil 3'te TCG algoritmasının ürettiği sonuçlara göre her bir iterasyon sayısı için atanan iterasyon değerleri grafiği gösterilmiştir. Buna göre CNR mantığ 1 baz alınarak grafiğin en yüksek değeri belirlenir. Sonrasında bu değere karşılık gelen iterasyon sayısı bulunur ve bulunan iterasyon sayısı kullanılarak görüntü oluşturulur. TCG algoritması için İSB 
algoritmasının belirlediği iterasyon sayısı, en yüksek iterasyon değerine $(10,62)$ karşılık gelen 20.iterasyondur.

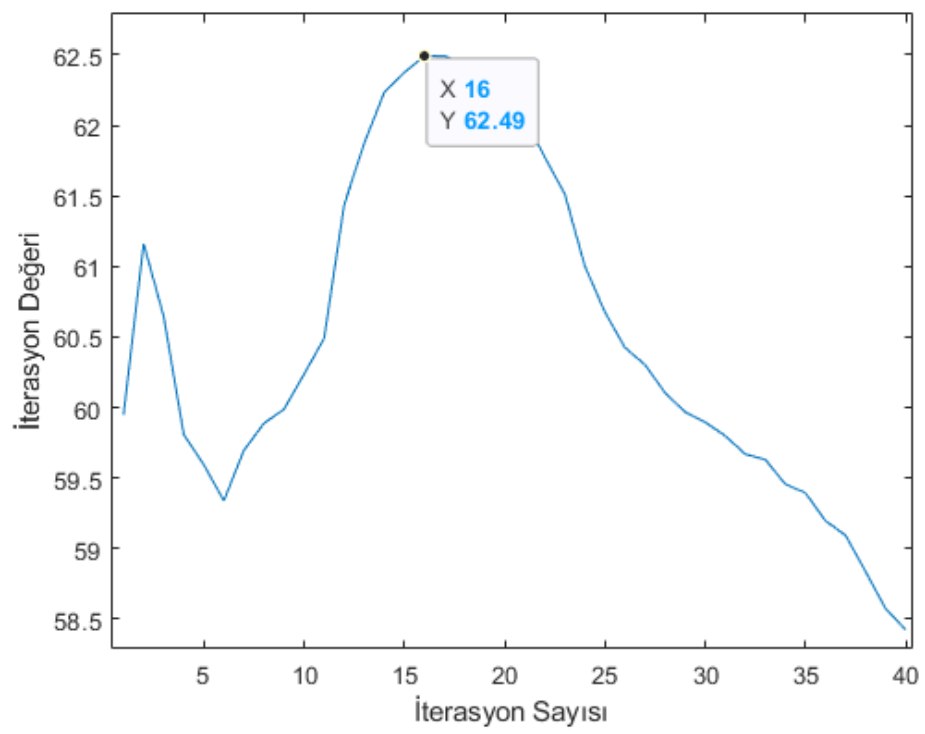

Şekil 4. BiCG için kaydedilen iterasyon sayısı belirleme algoritması grafiği

Şekil 4'te de TCG algoritmasına entegre edilen İSB algoritması grafiği gibi BiCG algoritmasının iterasyon sayısı ve değerleri grafiği gösterilmiştir. Grafiğin en yüksek değerine $(62,49)$ karşılık gelen iterasyon sayısı (16) belirlenmiştir ve bu iterasyon sayısı kullanılarak görüntü oluşturulmuştur (Şekil 2c ve 2d).

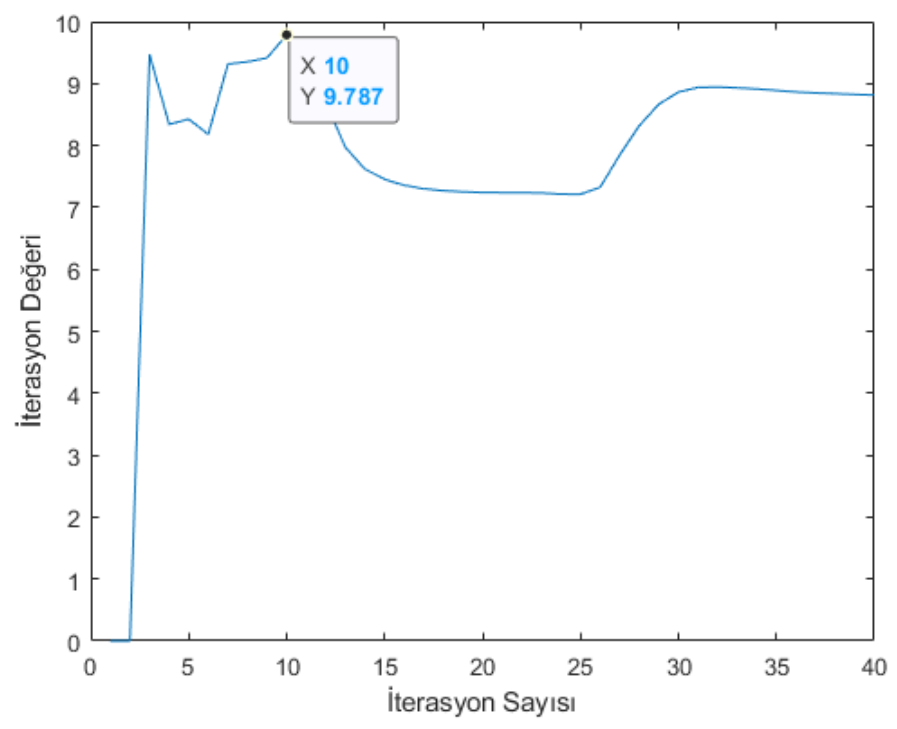

Şekil 5. TFQMR için kaydedilen iterasyon sayısı belirleme algoritması grafiği

Şekil 5'te TFQMR algoritmasına entegre edilen İSB algoritmasının ürettiği iterasyon değerleri ve sayıları gösterilmiştir. Buna göre en yüksek iterasyon değerine $(9,787)$ karşılık gelen iterasyon sayısı 10 olarak belirlenmiştir. Elde edilen iterasyon sayısı ile Şekil 2e ve 2f'deki görüntü oluşturulmuştur. 
Bu deneyler 1şığında CNR benzeri İSB algoritmamızın düzgün bir şekilde çalıştığı gösterilmiştir. Fakat bazı durumlarda özellikle matris sistemlerinin çözümlerinin daha da zorlaştığı durumlarda algoritma ilk 5 iterasyon sayısı ve 50. iterasyon sayısından büyük iterasyon sayıları için yüksek değerler üretebilmektedir. $\mathrm{Bu}$ da yanlış görüntüler oluşmasına sebep olabiliyor. Bu yüzden üretilen iterasyon değerleri sınırlandırılmıştır ve ilk 5 iterasyon değeri ve 50. iterasyondan sonraki değerler tarama değerlerinden çıkarılmıştır.

\section{Sonuç ve Yorum}

DOT sistemleri optik görüntüleme sistemlerindendir. Optik görüntüleme sistemlerinin kalibrasyon, veri alma, verileri işleme, görüntü verilerini oluşturma gibi aşamaları bazı dezavantajlara sahiptir. Bu aşamalardaki hataları en aza indirmek ve en uygun algoritmaları ve sistemi tasarlamak oldukça önem arz etmektedir. Bu yüzden DOT sistemlerinde görüntü oluşturma aşaması oldukça önemlidir. Bu aşamada kullanılan geri çatım teknikleri sistemlere özgü olarak düzgün bir şekilde belirlenebilmektedir[12-15]. Fakat bu aşamada kullanılan geriçatım teknikleri iteratif tekniklerdir ve bu yüzden düzgün bir şekilde görüntü verisi işleyebilmek için doğru iterasyon sayısını belirlemek gerekmektedir. Literatürde bunun için özelleşmiş belli algoritmalar kullanılmaktadır. Leğrisi, bu algoritmalardan en yaygın kullanılanıdır[16, 17]. Fakat L-eğrisi, hem sistemimiz için uygun olmadığından hem de L-eğrisi metotunun eğrisindeki iterasyon noktasının doğru bir şekilde belirlenebilmesi aşamasında hala zorluklar yaşanmaktadır[17]. Bu sebeple hem sistemimize uygulanabilecek hem de L-eğrisi algoritmasına alternatif olabilecek bir algoritma geliştirdik.

$\mathrm{Bu}$ algoritma CNR mantığına benzer bir şekilde çalışmaktadır. CNR'ın çalışma mantığında bir resmin kalitesini kontrast-gürültü oranını belirleyebilen bir sayısal parametre vardır. $\mathrm{Bu}$ parametre kontrast farkından yararlanılarak üretilir[15]. Aynı şekilde geri çatım algoritmalarının sayısal görüntü verileri incelendiğinde bu tarz bir sayısal fark olduğu görülmüştür. Bu sayısal fark ne kadar yüksek olursa oluşturulan görüntünün o kadar gerçeğe yakın olduğu tespit edilmiştir. Bu sebeple CNR benzeri bir çalışma mantığı olan bir İSB algoritması tasarlanmış ve TCG, BiCG ve TFQMR algoritmalarına entegre edilmiştir[15].

$\mathrm{Bu}$ algoritmada her bir geri çatım algoritmasının ürettiği sonuçlar belli toleranslarda iterasyon değerleri ile ifade edilmektedir. Her bir algoritmanın kendi özelinde her iterasyon sayısına karşılık gelecek şekilde bir iterasyon değeri üretilmektedir. $\mathrm{Bu}$ iterasyon değeri ne kadar büyük olursa ortamdaki lezyon ile ortam arasındaki fark o kadar büyük olabilmekte ve lezyonun daha net bir görüntüsü elde edilmektedir.

$\mathrm{Bu}$ çalışmada elde edilen görüntüler ile bu algoritmanın düzgün bir şekilde çalıştığı ve diğer İSB algoritmalarına alternatif olabileceği gösterilmiştir. Fakat geliştirdiğimiz İSB algoritması belli aralıkların dışına çıkıldığı zaman düzgün sonuçlar üretemediği gözlemlenmiştir. Bu yüzden belli bir iterasyon aralığında çalıştırılmaktadır. Bu sebeple sonraki çalışmalarda bu dezavantajın üzerinde durulacaktır ve algoritmanın eksikliği giderilmeye çalışılacaktır.

\section{Araştırmacıların Katkı Oranı Beyanı}

Gençay Sevim: Araştırma, Metodoloji, Yazılım, Kaynak/Materyal Temini

Yiğit Ali Üncü: Yazılım, Veri İyileștirme

Murat Canpolat: Kavramsallaştırma, Proje Yönetimi

\section{Destek ve Teşekkür Beyanı}


Çalışma kapsamında kullanılan MATLAB programları, Akdeniz Üniversitesi, Bilgi İşlem Dairesi Başkanlığı ve Eskişehir Teknik Üniversitesi, Bilgi İşlem Dairesi Başkanlığı tarafından sağlanan lisansa sahiptir. Bu çalışma Gençay SEVİM' in yüksek lisans tezinden türetilmiştir.

\section{Çatışma Beyanı}

$\mathrm{Bu}$ çalışmanın yazarları olarak herhangi bir çatışma beyanımız bulunmadığını bildiririz.

\section{Etik Kurul Onayı ve/veya Aydınlatılmış Onam Bilgileri}

$\mathrm{Bu}$ çalışmanın yazarları olarak herhangi bir etik kurul onayı ve/veya aydınlatılmış onam bilgileri beyanımız bulunmadığını bildiririz.

\section{Kaynakça}

[1] S. Sabir, S. Cho, D. Heo, K. Hyun Kim, S. Cho, and R. Pua, "Data-specific mask-guided image reconstruction for diffuse optical tomography," Appl. Opt., 59, 9328-9339, 2020.

[2] J. Yoo et al., "Deep learning diffuse optical tomography," IEEE Trans. Med. Imaging, 39(4), 877-887, 2020.

[3] E. Y. Chae et al., "Development of digital breast tomosynthesis and diffuse optical tomography fusion imaging for breast cancer detection," Sci. Rep., 10(1), 13127, 2020.

[4] A. P. Gibson, J. C. Hebden, and S. R. Arridge, "Recent advances in diffuse optical imaging," Phys. Med. Biol., 50(4), R1-43, 2005.

[5] D. A. Benaron and D. K. Stevenson, "Optical time-of-flight and absorbance imaging of biologic media," Sci., 259 (5100), 1463-1466, 1993.

[6] B. W. Pogue and M. S. Patterson, "Frequency-domain optical absorption spectroscopy of finite tissue volumes using diffusion theory," Phys. Med. Biol., 39 (7), 1157-1180, 1994.

[7] A. Siegel, J. J. Marota, and D. Boas, "Design and evaluation of a continuous-wave diffuse optical tomography system," Opt. Express, 4 (8), 287, 1999.

[8] S. L. Jacques, "Optical properties of biological tissues: A review," Phys. Med. Biol., 58(11), R37, 2013.

[9] Y. Hoshi and Y. Yamada, "Overview of diffuse optical tomography and its clinical applications," J. Biomed. Opt., 21 (9), 091312, 2016.

[10] R. C. Haskell, L. O. Svaasand, T.-T. Tsay, T.-C. Feng, B. J. Tromberg, and M. S. McAdams, "Boundary conditions for the diffusion equation in radiative transfer," J. Opt. Soc. Am., 11 (10), 2727-2741, 1994.

[11] T. Durduran, R. Choe, W. B. Baker, and A. G. Yodh, "Diffuse optics for tissue monitoring and tomography," Rep. Prog. Phys., 73 (7), 076701, 2010.

[12] R. J. Gaudette et al., "A comparison study of linear reconstruction techniques for diffuse optical tomographic imaging of absorption coefficient," Phys. Med. Biol., 45 (4), 1051, 2000.

[13] T. Mercan, G. Sevim, Y. A. Üncü, U. Serkan, H. Ö. Kazanc1, and M. Canpolat, "The comparison of reconstruction algorithms for diffuse optical tomography," Süleyman Demirel Üniversitesi Fen Edebiyat Fakültesi Fen Dergisi, 14 (2), 285-295, 2019.

[14] G. Sevim, T. Mercan, Y. A. Uncu, and M. Canpolat, "A new reconstruction technique used in Diffuse Optical Tomography System," 2017 21st National Biomedical Engineering Meeting (BIYOMUT), IEEE, 2018, pp. i-iv.

[15] G. Sevim, "Difüz optik tomografide kullanılan geri çatım tekniğinde görüntü kalitesini arttıracak düzenlemeler yaparak görüntü oluşturma ve elde edilen görüntüleri karş1laştırma,” Y.L. Tezi, Biyofizik ABD. Akdeniz Üniversitesi, Antalya, Türkiye, 2016.

[16] P. C. Hansen, “Analysis of Discrete Ill-Posed Problems by Means of the L-Curve," SIAM Rev., 34 (4), 561-580, 1992.

[17] A. Cultrera and L. Callegaro, "A simple algorithm to find the L-curve corner in the regularisation of ill-posed inverse problems," IOP SciNotes, 1 (2), 025004, 2020.

[18] M. H. Gutknecht, A Brief Introduction to Krylov Space Methods for Solving Linear Systems. in Frontiers of Computational Science, Berlin, Heidelberg: Springer, 2007, pp 53-62.

[19] R. Fletcher, "Conjugate gradient methods for indefinite systems," in Numerical analysis, Springer, 1976, pp. 73-89.

[20] R. E. Bank and T. F. Chan, "A composite step bi-conjugate gradient algorithm for nonsymmetric linear systems," Numer. Algorithms, 7, 1-16, 1994.

[21] G. Ortega, E. M. Garzón, F. Vázquez, and I. García, "The BiConjugate gradient method on GPUs,” J. Supercomput., 64 (1), 49-58, 2013. 
[22] R. W. Freund and N. M. Nachtigal, "QMR: a quasi-minimal residual method for non-Hermitian linear systems," Numer. Mat., 60 (1), 315-339, 1991.

[23] R. W. Freund, "A transpose-free quasi-minimal residual algorithm for non-hermitian linear systems,” SIAM J. Sci. Comput., 14 (2), 470-482, 1993. 